\title{
O DISCURSO DE FORMANDOS DO CURSO DE LETRAS: "FALTA COESÃO, FALTA COERÊNCIA NO TEXTO DE UMA MENINA DE 10 ANOS!"
}

\author{
EL DISCURSO DE LOS ESTUDIANTES DEL CURSO DE LETRAS: "FALTA COHESIÓN, FALTA DE \\ COHERENCIA EN EL TEXTO DE UNA NIÑA DE 10 AÑOS!"
}

\section{THE DISCOURSE OF UNDERGRADUATE LANGUAGE STUDENTS: "LACK OF COHESION, LACK OF COHERENCE IN THE TEXT OF A 10-YEAR-OLD GIRL!"}

\author{
Orlando de Paula* \\ Universidade de Taubaté
}

\begin{abstract}
RESUMO: Nosso intuito neste artigo é discutir as formas de manifestação dos conceitos de coesão e coerência textuais em textos produzidos por formandos do curso de Letras de universidades brasileiras. Trata-se de uma pesquisa cuja abordagem apoia-se no conceito de dialogismo e no conceito de heterogeneidade(s) enunciativa(s). Partimos do pressuposto de que o discurso dos formandos é constitutivamente heterogêneo, fato que pode ser captado na superfície textual por meio de marcas relacionadas com o conceito de heterogeneidade mostrada marcada. Como resultado, constatamos que os posicionamentos discursivos dos formandos revelam formações discursivas ligadas ao discurso didático e pedagógico, marcado, em geral, por uma atitude prescritivo-normativa, e que as referências à coesão e à coerência textuais indiciam noções diversas, ancoradas numa concepção tradicional de linguagem.
\end{abstract}

PALAVRAS-CHAVE: coesão e coerência textuais; heterogeneidade enunciativa; dialogismo.

RESUMEN: Nuestro objetivo en este trabajo es examinar e investigar las formas de manifestación de los conceptos de cohesión y coherencia textual en textos producidos por los estudiantes del curso de Letras de las universidades brasileñas. Se trata de una investigación cuyo enfoque es compatible con el concepto de dialogismo y el concepto de heterogeneidad(s) enunciativas(s). Estamos trabajando en el supuesto de que el discurso de los educandos es constitutivamente heterogéneo, un hecho que se puede recoger en la superficie textual por medio de marcas relacionadas con el concepto de heterogeneidad marcado y no marcado. De acuerdo con el resultado, constatamos que el posicionamiento discursivo de los estudiantes revela formaciones discursivas vinculadas al discurso didáctico y pedagógico, marcado generalmente por una actitud prescriptiva normativa, y que las referencias a cohesión y coherencia textual son las indicaciones de diversos conceptos, anclados en una concepción tradicional del lenguaje.

PALABRAS CLAVE: cohesión y coherencia textual; heterogeneidad enunciativa; dialogismo.

ABSTRACT: Our aim in this article is to discuss the way the concepts of textual cohesion and coherence are manifested in texts produced by undergraduate Language students enrolled in Brazilian Universities. This research is based on the concept of dialogism and the concept of enunciative heterogeneity. We have departed from the presupposition that the discourse of the undergraduate students is constitutively heterogeneous; and thus it can be captured from the textual surface by means of marks related to the marked heterogeneity concept. According to the results, we found that the discursive positioning of these students reveal discursive formations linked to didactic and pedagogical discourse, generally marked by a prescriptive-normative attitude, and that the references to textual cohesion and coherence indicate diverse notions, based on a traditional view of language.

KEYWORDS: textual cohesion and coherence; enunciative heterogeneity; dialogism.

\section{INTRODUÇÃO}

O que pensamos quando ouvimos no meio acadêmico um professor dizer que um texto não tem coesão nem coerência? Podemos pensar no conceito que ele está atribuindo a esses termos e perguntar: não estaria havendo uma generalização e simplificação no uso desses conceitos? E quando se trata de um professor recém-formado ou de professores recém-formados do curso de Letras? Haveria também uma utilização generalizada desses conceitos? Para responder a essas questões, nosso intuito é discutir esse aspecto, uma vez que a coesão e a coerência textuais são temas praticamente recentes no Brasil, já que começaram a ser divulgados, juntamente com outros aspectos sobre o texto, na década de 80, por estudiosos e pesquisadores quando da introdução da Linguística Textual, doravante LT, no país.

Nosso objetivo é identificar e discutir o(s) conceito(s) de coesão e de coerência textual(ais) que fundamenta $(\mathrm{m})$ o discurso de formandos do curso de Letras, a partir de textos produzidos por esses alunos

* Professor efetivo de Língua Portuguesa da Universidade de Taubaté. Email: orlpa@uol.com.br. 
ao responderem uma questão discursiva da prova de Linguística e Língua Portuguesa do antigo Exame Nacional de Cursos, antigo Provão ${ }^{1}$. Para sustentar essa pesquisa, assumimos, do ponto de vista teórico, que a manifestação verbal do discurso desses universitários se dá por sujeitos constituídos social e historicamente. Para tanto, recorremos ao conceito de dialogismo de Bakhtin (1997, 2003) e ao conceito de heterogeneidade(s) enunciativa(s) de Authier-Revuz (1990, 2004). Partimos do pressuposto de que o discurso desses formandos é constitutivamente heterogêneo, fato que pode ser captado na superfície textual por meio da heterogeneidade mostrada marcada e não marcada (AUTHIER-REVUZ, 1990; 2004). No entanto, focalizaremos neste trabalho apenas os casos que representam a noção de heterogeneidade mostrada marcada. Trata-se de uma perspectiva enunciativo-discursiva que permite lançar um olhar pouco comum sobre o tema que se caracteriza não só pela análise de marcas linguísticas explícitas, mas também pela análise dos efeitos de sentido que essas marcas enunciam, marcas essas que serão vistas como posicionamento(s) em um campo discursivo, conforme Maingueneau (1991), tomados como indicações das posições teóricas assumidas por esses acadêmicos.

\section{PRESSUPOSTOS TEÓRICOS: DIALOGISMO E HETEROGENEIDADE(S) ENUNCIATIVA(S)}

Para ancorar nosso estudo, retomamos o conceito de heterogeneidade(s) enunciativa(s) de Authier-Revuz (1990; 2004), uma vez que partimos do pressuposto de que nos textos de formandos do curso de Letras, material de análise, ocorre, de forma mais explícita, a manifestação da noção de heterogeneidade mostrada marcada. Por meio dessas manifestações, pode-se observar uma relação dialógica entre interlocutores e entre discursos, isto é, a relação entre o mesmo e o outro.

De acordo com Authier-Revuz (1990), o conceito de heterogeneidade enunciativa está relacionado a duas formas de heterogeneidade: a heterogeneidade mostrada no discurso e a heterogeneidade constitutiva do discurso. No primeiro tipo, formas linguísticas - marcadas ou não marcadas - inscrevem o outro na sequência do discurso, como o discurso direto, as aspas, as formas de retoques ou de glosa, o discurso indireto livre, a imitação, a ironia, etc., causando uma alteração na sua aparente unicidade.

As formas marcadas representam

[…] uma negociação com as forças centrífugas, de desagregação, da heterogeneidade constitutiva: elas constroem no desconhecimento desta, uma representação da enunciação, que, por ser ilusória, é uma proteção necessária para que um discurso possa ser mantido. (AUTHIER-REVUZ, 1990, p. 33).

Por sua vez, as formas não marcadas representam a incerteza que caracteriza a referência ao outro, uma forma de negociação com a heterogeneidade constitutiva, que joga "com a dissolução do outro no um, onde este, precisamente aqui, pode ser enfaticamente confirmado, mas também onde pode se perder" (p. 34).

No segundo tipo de heterogeneidade, a constitutiva, as formas não são explícitas, mas próprias da natureza da linguagem. Trata-se de formas não marcadas na superfície, mas definidas pela interdiscursividade, ou seja, pela relação que todo discurso mantém com outros discursos.

Embora haja uma distinção entre o conceito de heterogeneidade do sujeito e do discurso de Autheir-Revuz (1990) e o de dialogismo de Bakhtin (1997), convém lembrar que aquele foi formulado a partir do conceito bakthiniano e da abordagem psicanalítica que vê o sujeito como efeito da linguagem, numa leitura lacaniana de Freud.

De acordo com Bakhtin (1997), o dialogismo nasce da interação verbal (a relação do eu com o outro), pois toda palavra é determinada pelo fato de proceder de alguém e se dirigir a alguém, constituindo-se na da interação entre o locutor e o ouvinte. A palavra é, portanto, produto da interação social e como tal torna-se um lugar para manifestação ideológica. Dessa forma, o dialogismo passa a ser uma condição constitutiva do sentido. Bakhtin (1997) afirma que

\footnotetext{
${ }^{1}$ Este artigo foi elaborado a partir da tese de doutorado "Noções de coesão na visão de formandos em Letras", conforme Paula (2008). Trata-se, portanto, de um recorte dessa tese.

Forum linguistic., Florianópolis, v.11, n.4, p.444-456, out./dez.2014
} 
[...] a verdadeira substância da língua não é constituída por um sistema abstrato de formas linguísticas, nem pela enunciação monológica isolada, nem pelo ato psicofisiológico de sua produção, mas pelo fenômeno social da interação verbal, realizada através da enunciação ou das enunciações. A interação verbal constitui assim a realidade fundamental da língua. (BAKHTIN, 1997, p.123)

Bakhtin (2003, p. 274) chama a atenção para a importância do papel de sujeitos ativos, interagindo na/pela linguagem, pois, para ele, o enunciado como "real unidade da comunicação discursiva" comporta um falante e um ouvinte, como participantes reais da comunicação discursiva. Assim, não se tem um falante ativo e um ouvinte passivo, mas sujeitos atuantes, numa situação de comunicação discursiva, cuja natureza é ativamente responsiva.

Para confirmar essa noção de interação e o caráter dialógico, Bakhtin (2003) enfatiza a atuação do homem em sociedade e a consciência deste sobre o outro ao tratar da obra de Dostoievski. Opondo-se ao enfoque monológico, o autor continua a discussão sobre o caráter dialógico da linguagem e a tomada de consciência do outro pelo homem:

Natureza dialógica da consciência, natureza dialógica da própria vida humana. A única forma adequada de expressão verbal da autêntica vida do homem é o diálogo inconcluso. A vida é dialógica por natureza. Viver significa participar do diálogo: interrogar, ouvir, responder, concordar, etc. Nesse diálogo o homem participa inteiro e com toda a vida: com os olhos, os lábios, as mãos, a alma, o espírito, todo o corpo, os atos. Aplica-se totalmente na palavra, e essa palavra entra no tecido dialógico da vida humana, no simpósio universal. (BAKHTIN, 2003, p. $348)$.

Por sua vez, na abordagem psicanalítica, que se apoia na teoria saussureana e na leitura lacaniana de Freud, o inconsciente "[...] produz a dupla concepção de uma fala fundamentalmente heterogênea e de um sujeito dividido." (AUTHIER-REVUZ, 1990, p. 28). Trata-se de um discurso atravessado pelo inconsciente, cujo sujeito não é uma "entidade homogênea exterior à linguagem, mas o resultado de uma estrutura complexa, efeito da linguagem: sujeito descentrado, dividido, clivado [...]” (AUTHIER-REVUZ, 1990, p. 28). Assim, pode-se escutar na cadeia discursiva, não intencionalmente, a polifonia de todo discurso.

Considerando, portanto, que o conceito de dialogismo bakhtiniano está ligado ao funcionamento dialógico da linguagem (diálogo entre interlocutores e entre discursos), e o conceito de Authier-Revuz (1990), à constituição heterogênea do sujeito e do discurso, o qual é considerado como efeito da linguagem, pois produzido por um sujeito dividido e descentrado, podemos propor, ao menos sob esse aspecto, uma aproximação entre uma concepção dialógica de linguagem e uma concepção de linguagem constituída pelas heterogeneidades enunciativas.

Isto posto, partimos do pressuposto de que nos textos dos formandos em Letras ocorre, de forma mais explícita, a manifestação da noção de heterogeneidade mostrada marcada caracterizada pelo uso de: a) palavras específicas para fazer menção à coesão e à coerência textuais; b) palavras não específicas para fazer menção à coesão textual; c) palavras que não fazem menção nem específica nem não específica à coesão textual.

\section{PROCEDIMENTOS METODOLÓGICOS}

O corpus selecionado para esta análise constitui-se de 161 textos ${ }^{2}$ produzidos por formandos do curso de Letras, sendo 104 de universidades públicas, doravante UNIPUB, e 57 universidades particulares, doravante UNIPAR, ao responderem a questão discursiva da prova de Linguística e Língua Portuguesa, do Exame Nacional de Cursos (ENC) 2001, mais conhecido como Provão, o qual foi substituído, em 2004, pelo Exame Nacional de Desempenho de Estudantes-ENADE³. Tal questão tinha como pressuposto o conhecimento sobre coesão textual, pois versava sobre o uso de mecanismos coesivos em um texto

\footnotetext{
${ }^{2}$ Estes textos estão integrados a um corpus maior de 210 textos de alunos de universidades brasileiras, da esfera pública e particular, os quais foram analisados e apresentados em uma tese de doutorado. Para este artigo, foi feito um recorte com 161 textos, os quais foram distribuídos conforme as seções em que a análise é apresentada: 93 na seção 4, 60 na seção 5 e 8 na seção 6.
}

${ }^{3}$ Este material de análise foi fornecido pelo INEP, conforme ofício de autorização MEC/INEP/DAES N ${ }^{\circ}$ O01708/2002, de 02 de abril de 2002. 
produzido por uma menina de 10 anos. Na sequência, apresentamos a questão como consta no caderno de prova do $\mathrm{ENC} / 2001^{4}$ :

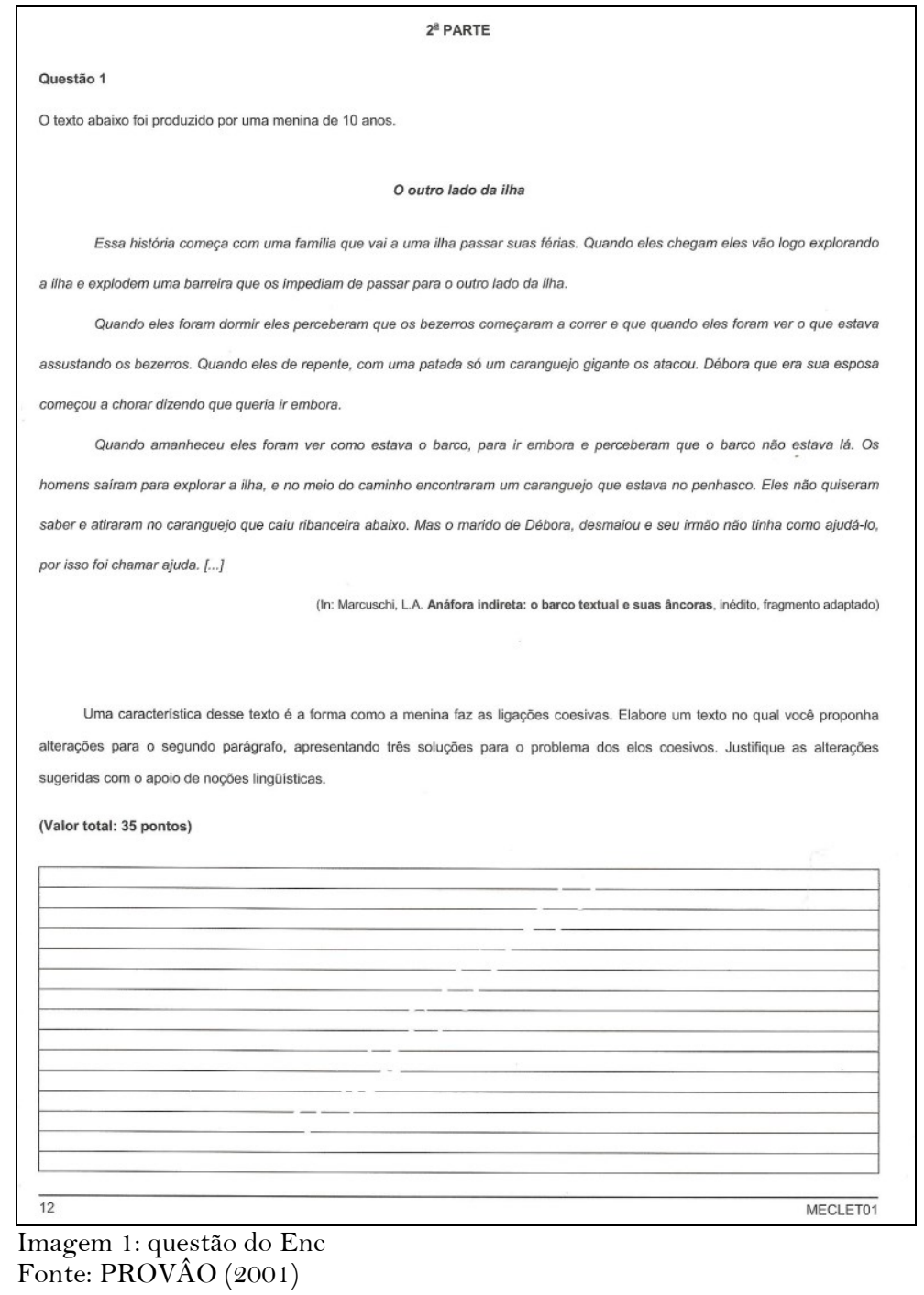

Nos textos selecionados, ao fazermos um levantamento da seleção lexical feita pelos formandos, localizamos, numa réplica mais próxima da noção de heterogeneidade mostrada marcada de Authier-Revuz (1990), três tipos de textos constituídos de justificativa com comentários e/ou explicações, caracterizados pelo uso de: a) palavras específicas para fazer menção à coesão e à coerência textuais; b) palavras não específicas para fazer menção à coesão e à coerência textuais; c) palavras que não fazem menção nem específica, nem não específica à coesão textual.

No primeiro tipo, foram agrupados 93 textos (33 UNIPAR e 60 UNIPUB) que apresentam enunciados com marcas específicas sobre coesão e coerência textuais, como substantivos, advérbios ou adjetivos, como "coesão", "coesivamente" e "coesivo"; ou expressões formadas por substantivos e adjetivos, substantivos e substantivos ou adjetivos e adjetivos, como "coesão textual”, “coesão e coerência”, "coesivo e coerente”. No segundo, foram agrupados 60 textos (20 UNIPAR e 40 UNIPUB) que não apresentam marcas específicas como as indicadas no item anterior, mas com a presença de palavras e/ou expressões não específicas como a conjunção "logo”, “conjunção”, "pronome eles”, "há repetições”, "muita repetição”, “idéia de resultado” etc. Por fim, no terceiro, figuram 8 textos (4 UNIPAR e 4 UNIPUB) que não fazem menção específica nem não especifica à coesão textual, mas remetem à coerência textual, por meio das palavras "coerência" e "coerente"; à gramática normativa, por meio das expressões "gramática normativa” e "normas/regras da língua culta”; e à linguística, por meio da palavra "linguística”.

${ }^{4}$ PROVÃO 2001- Exame nacional de Cursos: Disponível em:<http://www1.folha.uol.com.br/folha/educacao/2001-provao-letras.pdf $>$ Acesso em: 01 maio 2008.

Forum linguistic., Florianópolis, v.11, n.4, p.444-456, out./dez.2014. 
Salientamos que os textos apresentados na análise estão em sua redação original.

\section{HETEROGENEIDADE MOSTRADA MARCADA: USO DE PALAVRAS ESPECÍFICAS}

Nesta etapa de análise, utilizamos 33 textos de alunos de UNIPAR e 60 textos de alunos de UNIPUB. Nesses textos, organizamos um primeiro levantamento de palavras específicas que poderiam servir de indícios de noções de coesão e coerência textuais, conforme descrição no último parágrafo da seção anterior. Consideramos esse uso como fruto de um "[...] posicionamento em um campo discursivo." (MAINGUENEAU, 1991, p. 17-18).

Para exemplificar, passemos ao primeiro exemplo:

(1) A primeira solução para o texto seria a eliminação do excesso de pronomes que o mesmo contém, o que o tornaria menos repetitivo. Uma outra correção seria com relação a pontuação, feita as alterações teremos um texto mais coesivo. Por último teríamos que eliminar a citação que não cabe na construção desta frase: “...Débora que era sua esposa...”. Esposa de quem? O texto não faz referências anteriores, portanto não faz sentido, o texto deve ter coerência. (texto 35, UNIPAR, grifo nosso).

Nesse exemplo, há adjetivos que funcionam como modalizadores, os quais aparecem acompanhados de advérbios: "menos repetitivo", "mais coesivo". Assim, o enunciador sugere a eliminação do excesso de pronomes para que o texto-base se torne menos repetitivo. Nessa sugestão, a repetição se caracteriza como o problema do texto-base. A outra correção sugerida pelo enunciador relaciona a pontuação com a coesão, por meio da expressão "mais coesivo" (advérbio e adjetivo), em que "coesivo" foi tomado como uma referência à coesão textual. Para encerrar, o aluno sugere a eliminação da oração "Débora que era sua esposa", já que não estabelece referência a nenhum elemento anterior, fazendo uma associação desse fato com a coerência. Têm-se, então, os termos "coesivo" e "coerência" como índices do conceito de heterogeneidade mostrada marcada, isto é, palavras específicas usadas pelo enunciador para se referir à coesão e à coerência textuais. Observa-se, então, que, além dos adjetivos, outros modalizadores contribuem para caracterizar a atitude apreciativa do formando frente ao texto-base, como os substantivos "correção", "eliminação", "excesso"; as formas verbais "seria", "tornaria", "eliminar", "deve ter". Têm-se, assim, marcas que caracterizam de forma apreciativa a atitude do enunciador.

Vejamos o segundo escrito:

(2) Deve ser ampliado o trabalho de emprego dos pronomes, no caso do texto em que a menina empregou tentando dar coesão as frases numa atitude de insucesso. O problema dos elos coesivos deixa as frases sem sentido, como se ela quisesse dizer algo que não foi dito. Também deve sugerir que os alunos façam (mais) leituras de textos, de livros que sejam de seu interesse e que os alunos possam basear sua produção de textos na leitura feita, não imitar, mas observar a forma como os textos são estruturados e como são estabelecidas as ligações das orações e palavras que dão sentido ao texto e às frases. Nota-se também a repetição do pronome pessoal "eles", pois a aluna escreveu da forma como falamos. Sugere-se que seja feito um trabalho mostrando a diferença da forma como falamos e como escrevemos, dando ênfase à repetição dos pronomes na linguagem falada. (texto 27, UNIPAR, grifo nosso).

Em (2) ocorre o uso do substantivo "repetição". O acadêmico, para resolver o problema dos elos coesivos do

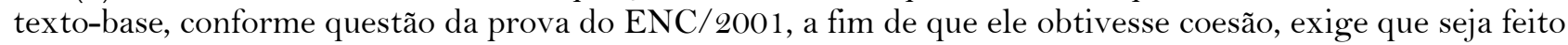
um trabalho que envolva a leitura de textos e de livros do interesse dos alunos para que possam "basear sua produção de texto na leitura feita". De acordo com (2), dessa forma os alunos saberão como os textos são estruturados e como são estabelecidas as ligações entre as orações e as palavras. Para esse acadêmico, que se coloca na posição de um professor a sugerir um método de ensino, a autora do texto-base não conseguiu dizer o que queria devido ao problema dos elos coesivos. Em seguida, chama a atenção para a "repetição" do pronome pessoal "eles", ocorrida no texto-base, e explica essa repetição como uma característica da modalidade falada, já que, para o enunciador, a autora desse texto procurou escrever da forma como se fala. $\mathrm{O}$ formando relaciona a repetição com a modalidade oral e sugere um trabalho que mostre a diferença entre as modalidades falada e escrita, novamente na posição de um professor a propor uma metodologia de ensino. 
Por isso, detectamos em (2) que a repetição não é vista como um erro a ser corrigido, mas como uma característica da modalidade falada que não pode ocorrer na modalidade escrita, já que ele sugere o trabalho "mostrando a diferença da forma como falamos e como escrevemos". Em (2), a referência à coesão textual é feita por meio da palavra "coesão", palavra específica tomada como índice do conceito de heterogeneidade mostrada marcada. Não consideramos a expressão "elos coesivos" em (2), pois esta já esta presente no enunciado da questão.

No exemplo (3),

(3) Gnerre comenta que "as produções lingüísticas adquirem valor se realizados no contexto social e cultural apropriado. Neste texto o escritor escreveria baseando-se no contexto que ele vivenciava assemelhando-se a língua falada e falta de compromisso com as regras da língua normativa que de certa forma prejudicou a relação coesiva. (texto 126, UNIPUB, grifo nosso)

com a citação de "Gnerre", o acadêmico usa de um discurso de autoridade para justificar a falta de "relação coesiva" do texto-base. Nesse exemplo, a citação é iniciada com aspas, mas não há indicação de seu término, pois não há aspas finais. Apoiando-se nesse estudioso da linguagem, o aluno justifica o fato de a autora do texto-base, a quem se refere com o termo "escritor", escrever baseando-se no "contexto" que vivenciava, e vê, nesse ato, semelhanças com a prática oral/falada, fato que não compromete a autora do texto-base com "as regras da língua normativa". Por estabelecer uma identificação do texto da menina com a modalidade falada e pelo fato de a menina não precisar seguir regras ou normas, muito menos estabelecer relações coesivas no texto, esse comentário indica que as normas da língua são prerrogativas apenas da modalidade escrita. Ao afirmar que "de certa forma prejudicou a relação coesiva", o enunciador procurou responder à questão proposta na prova do ENC/2001, já que esta afirmava haver a existência de "problemas coesivos" no texto-base. Assim, o uso da expressão "relação coesiva" como uma marca específica que faz remissão à coesão textual, e assim um índice do conceito de heterogeneidade mostrada marcada, relacionado ao uso do sintagma "as regras da língua normativa", indica um conceito de coesão ligado a uma atitude normativa do enunciador, isto é, uma atitude que indica rejeição a qualquer desvio da norma padrão (YAGUELLO, 1988).

Por sua vez, em (4),

(4) Falar e escrever bem implica não só no conhecimento da norma padrão, como também no momento de transmitir a mensagem, a qual deve admitir uma estrutura concisa para que o receptor compreenda o que foi transmitido e, assim, a comunicação tenha o efeito esperado. Um dos principais pontos indispensáveis na fala e, principalmente, na escrita é a coesão. Para que ela aconteça é necessário: expressar-se bem; evitar repetições de classes gramaticais (digo: das mesmas classes gramaticais); aplicar corretamente os sinais de pontuação, entre outros. No entanto, essas características não foram apresentadas no texto acima, causando, assim, uma má interpretação textual no que diz respeito ao primeiro enunciado do segundo parágrafo. (texto 162, UNIPUB, grifo nosso)

o enunciador emprega a expressão "norma padrão", a qual, considerado o contexto, foi tomada como uma expressão que indica uma atitude normativa por parte do enunciador, e a palavra "coesão", como uma referência à coesão textual e como um termo específico, que relacionamos ao conceito de heterogeneidade mostrada marcada. Para o enunciador, "falar e escrever bem implica" conhecer a norma padrão e saber se comunicar. Segundo o formando, a coesão é consequência, dentre outras características, de expressar-se bem, da não repetição de classes gramaticais, do emprego correto dos sinais de pontuação, características que afirma não ocorrerem no texto-base, o que leva a uma "má interpretação" desse texto. Tais características indicam também uma atitude apreciativa do formando. Tem-se, assim, em (4), indícios de uma noção de coesão marcada por atitudes normativa e apreciativa por parte do enunciador.

Já em (5),

(5) Este pequeno texto, poderia ter sido melhor estruturado. No início do segundo parágrafo noto que há uma repetição da palavras "ele" \#que não é necessária. Também noto que poderia ser 
empregado elementos coesivos e uma melhor pontuação. As idéias, também deveriam ter uma melhor organização. (texto 54, UNIPAR, grifos nossos) 5

ocorre o uso do substantivo 'repetição' pelo aluno para se referir ao pronome "ele". Segundo o enunciador, a repetição desse pronome não é necessária, já que o texto-base poderia ser melhor estruturado. Com esse comentário do enunciador, a repetição é identificada como um problema do texto-base. De acordo com esse modo de tratar a repetição, o acadêmico não justifica a não necessidade dessa repetição. Na avaliação que ele faz do texto-base, utiliza marcas como "poderia ter sido" (verbo modal 'poder' no futuro do pretérito) e "poderia ser empregado" (verbo modal 'poder' no futuro do pretérito) para suavizar essa avaliação. Já com "deveria ter uma melhor organização" (verbo modal 'dever' no futuro do pretérito) há um tom avaliativo mais evidente. A expressão "elementos coesivos" foi tomada como uma referência à coesão textual e como um índice do conceito de heterogeneidade mostrada marcada. Assim, esse universitário, para resolver o problema do texto base, ou seja, a repetição, sugere o emprego de elementos coesivos e o emprego dos sinais de pontuação.

Podemos conhecer, com esses exemplos, o levantamento de palavras específicas que foram consideradas como indícios de noções de coesão textual. Uma característica que nos chama a atenção, conforme exemplo (1) e (5), é que a repetição que ocorre no texto-base é motivo de uma avaliação por parte do formando que a considera como um problema, sem especificá-lo, e, por isso, sugere a sua eliminação. Essa postura indica o predomínio de uma atitude apreciativa dos formandos frente ao texto-base por denotar um juízo sobre esse texto. Essa posição talvez se deva ao fato de atender ao enunciado da questão que solicita solução para o problema dos elos coesivos. Nesse caso, ele é induzido a apontar os problemas, dentre eles, a repetição. Além disso, a repetição em textos de alunos é geralmente apontada, no discurso de diversos professores, apenas como um problema e não como recurso a ser utilizado na produção textual.

Especificamente sobre a repetição, vários autores que discorreram sobre esse fenômeno em seus estudos não a veem como problema. Vejamos: Marcuschi (2002) a considera como estratégia de formulação para o discurso oral; Koch (1997a) corrobora Marcuschi e acrescenta que a repetição é um recurso essencial no estabelecimento da coesão textual; Castilho (1998) também defende o papel da repetição em textos falados; Charolles (1997 [1978]) considera-a como uma das metarregras de coerência; Beaugrande e Dressler (1981), por seu turno, apresentam a repetição como um dos mecanismos que permitem a reutilização, a modificação ou a compreensão das estruturas e dos padrões usados previamente no processamento de fragmentos textuais, contribuindo tanto para a estabilização do sistema textual, quanto para a economia de esforços no processamento.

Também percebemos que, na argumentação desses autores, a repetição é tratada como um mecanismo coesivo utilizado pelo produtor do texto; ao mesmo tempo, torna-se um elemento essencial para a coerência do texto. Embora esse fenômeno seja uma estratégia geralmente apontada como uma característica de textos pertencentes à modalidade falada, não o é exclusivamente. Contudo, essa concepção da repetição como uma estratégia de construção do texto não aparece nos comentários dos formandos sobre o textobase, uma vez que a atitude deles, na maioria dos textos, é apontar a repetição como uma característica sempre negativa, como um erro a ser evitado. Talvez por influência da própria questão que solicita que o formando apresente uma solução para o "problema dos elos coesivos". Curiosamente, não se especifica, porém, que, no texto-base, a repetição do pronome "eles" provoque ambiguidade.

Caberia, aqui, uma explanação que Possenti (1993, p. 99) faz, do ponto de vista discursivo, de alguns mecanismos coesivos, dentre os quais inclui a repetição. Segundo esse autor,

[...] a repetição é um procedimento que serve a mais de uma finalidade, mas, sem dúvida, parece servir a esta: a clareza da interpretação. Por isso, aparece em discursos de cunho científico ou didático, por exemplo, e muito freqüentemente no discurso infantil, isto é, dirigido a crianças, representadas nele de determinada forma.

Possenti (1993) explica que, para atingir a clareza da interpretação, o locutor forma uma imagem de seu interlocutor no momento da enunciação de um discurso e, conforme a imagem, utiliza determinado elemento coesivo. Tal imagem pode ser positiva ou negativa. Se positiva, utilizará de anáforas por considerar que o interlocutor tem mais capacidade de entender; se negativa, usará da repetição. No caso do

\footnotetext{
${ }_{5}^{5}$ Os textos apresentados na análise encontram-se na forma original, isto é, tal qual se apresentam nos dados: sem correções ortográficas, com lacunas, etc., conforme informação no final da seção anterior.
} 
discurso infantil, dependendo da imagem que faz do ouvinte e da intenção, se o locutor quer ser claro, quer ser entendido, usa da repetição para facilitar a interpretação. Conclui que é por isso que a repetição é predominante nos textos infantis, dado que o público-alvo são crianças, embora os estudiosos da aquisição da linguagem saibam que "as crianças não necessitam desses recursos para acompanhar a narrativa" (POSSENTI, 1993, p. 101). E continua: "Na verdade, há uma imagem da criança como se ela fosse um pequeno idiota, e a linguagem e as temáticas da literatura infantil reforçam esta idéia. É uma imagem provavelmente equivocada, mas extremamente produtiva" (POSSENTI, 1993, p. 101).

Nesse sentido, há a possibilidade de a autora do texto-base, uma menina de 10 anos, ter procurado ser clara, dado o contexto em que o texto-base se insere e no qual se historiciza: trata-se de um resumo feito, a partir de uma história, por uma aluna de $5^{\text {a }}$ série, para ser lido em sala de aula para seus colegas e professor.

Isso posto, pode-se dizer que o uso de determinados substantivos por parte dos formandos do curso de Letras nos comentários feitos acerca do texto-base, dentre eles o uso recorrente, e genérico, do substantivo "repetição", é indício de uma atitude apreciativa e, também, de uma noção de coesão textual, se consideramos, como apresentado nos parágrafos anteriores, Koch (1997a), que a toma como um recurso essencial no estabelecimento da coesão textual, e Charolles (1997 [1978]), que a considera como uma das metarregras de coerência.

Esse uso demonstra uma posição enunciativa do formando e representa uma forma de avaliação do textobase, avaliação que revela uma atitude apreciativa por parte dos formandos que se põem a sugerir e/ou a exigir uma correção desse texto, talvez estimulados pelo enunciado da questão. Daí observar que, por meio dessas marcas, manifesta-se nos textos desses alunos um discurso indicador de uma reprodução do processo de ensino-aprendizagem na forma de discurso didático, uma vez que há uma simulação do acompanhamento da produção textual de um aluno pelo professor, como um simulacro de um procedimento didático, conforme Corrêa (2006).

Com a reprodução de um discurso didático, os formandos do curso de Letras colocam-se na situação de um professor que aponta a falta de coesão e a falta de coerência no texto-base e que apresenta os procedimentos que julga necessários para estabelecer a coesão e a coerência nesse texto. Tal procedimento didático ocorre em textos com indícios de noções de coesão e coerência textuais, as quais podem ser definidas ora como fatores independentes, ora como fatores dependentes, ora com a coerência como uma consequência da coesão. Essa atitude remete ao que diz Charolles (1997 [1978]), quando reflete sobre as estratégias de intervenção desenvolvidas pelo professor frente a textos escritos por alunos das primeiras séries. Charolles (1997 [1978], p. 42) afirma que "[...] os professores denunciam ingenuamente as malformações textuais que encontram nos textos dos alunos e ficam num estágio de avaliação pré-teórico [...]”. Parafraseando-o, pode-se dizer que os problemas apontados pelos acadêmicos do curso de Letras no texto escrito por uma menina de 10 anos tornam-se um protesto ingênuo, dadas as condições de produção desses textos (a prova do $\mathrm{ENC} / 2001)$ e as condições de formação desses acadêmicos, uma vez que eles parecem deter uma concepção "pré-teórica" e insuficiente da coesão e da coerência textuais. Da mesma forma, parecem querer reproduzir o papel de professor, de acordo com o imaginário que esses formandos constroem da banca examinadora.

Com essa análise, temos uma síntese da primeira forma de manifestação do conceito de coesão e de coerência textuais, isto é, uma síntese de palavras e expressões específicas por meio das quais os formandos fazem referência à coesão e à coerência textuais, palavras estas que foram tomadas como índices e relacionadas ao conceito de heterogeneidade mostrada marcada de Authier-Revuz (1990; 2004).

De acordo com esse levantamento, em 51,5\% dos textos de alunos de universidades particulares, a coesão textual não tem relação com a coerência textual, mas 48,5\% apresentam a coesão textual associada à coerência textual. Em relação aos textos de alunos de universidades públicas, predominam conceitos de coesão textual sem relação com a coerência textual, pois em $70 \%$ desses textos há apenas indícios de conceitos de coesão textual; somente em 30\% há indícios de coesão textual associada à coerência textual.

Nesses textos de alunos de universidades particulares e públicas, predominam conceitos de coesão e coerência textuais marcados pela presença de expressões normativas e de modalizadores indicadores, respectivamente, de atitudes normativa e apreciativa por parte do sujeito enunciador. 
Ao relacionar os conceitos de coesão e de coerência textuais, construídos nos textos dos formandos do curso de Letras, com a situação na qual esses textos foram produzidos, pode-se dizer que eles são resultado da relação dialógica entre os formandos, a questão do ENC/2001, o texto da menina que integra essa questão e a banca examinadora. Isso significa que os formandos, ao responderem à questão, interagiram com o autorinstitucional da questão, ao procurarem atender o solicitado; com a menina, por meio de uma avaliação da narrativa que esta escreveu e que figura na questão; e com a banca examinadora, uma vez que eles sabiam que sua resposta seria avaliada por uma banca. Por isso, a forma de manifestação desses formandos levou em conta, além da imagem construída do autor-institucional e da autora da narrativa, a imagem da banca avaliadora. Pode-se dizer também que há a relação entre os discursos que constituem esses sujeitos e os posicionamentos por eles assumidos (consciente ou inconscientemente) nos diversos campos de saber. Nessa relação, os formandos de UNIPAR e de UNIPUB analisaram o texto-base, apontando problemas, dentre os quais predomina a repetição de termos, assim como soluções para esses problemas. De acordo com esses conceitos, se a coesão e a coerência estão relacionadas com o emprego adequado de elementos coesivos (pronome, conjunções etc.), provavelmente o emprego inadequado desses elementos indicaria a falta de coesão e de coerência, critérios de textualidades que, segundo os formandos, não existem no texto escrito por uma menina de 10 anos.

\section{HETEROGENEIDADE MOSTRADA MARCADA: USO DE PALAVRAS NÃO ESPECÍFICAS}

Neste grupo de textos, a presença de indícios de conceitos de coesão e de coerência textuais foi observada em 60 textos, sendo 20 textos de alunos de UNIPAR e 40 de alunos de UNIPUB. Para esta forma de manifestação, a seleção lexical efetuada pelos formandos também foi considerada como indícios; entretanto, neste conjunto de textos não há o uso de marcas explícitas específicas sobre coesão textual como as classificadas no item anterior, mas há a presença de palavras não específicas que cumprem esse papel, como "conjunção", "pronome eles", "há repetições", "muita repetição", "idéia de resultado" etc., já que esse uso também pode ser considerado como fruto de um "[...] posicionamento em um campo discursivo." (MAINGUENEAU, 1991, p. 17-18). Nesse levantamento, embora não tenha havido referência à coesão textual por meio de palavras específicas, houve referência à coerência textual. Passemos aos exemplos:

(6) As alterações sugeridas foram: que se retira-se as repetições_do tipo - "quando e "eles" para maior evolução do texto. Segunda , o uso da pontuação, onde a vírgula pode ser considerada um aliada da continuidade mais expressiva para o texto. Por último, uma alteração na estrutura verbal menos pesada (como foram; começaram a correr; estava assustando) para maior coerência textual. (texto 3, UNIPAR, grifo nosso)

Nesse exemplo, o formando descreve as alterações sugeridas, propondo a retirada de conjunções e pronomes repetidos e o uso da vírgula para maior expressividade do texto. Depois, sugere a troca de alguns verbos para uma "estrutura verbal menos pesada". Destaca-se, nessa descrição, o uso de vários modalizadores como "maior evolução", "pode ser considerada", "mais expressiva", "menos pesada", o que indica uma atitude apreciativa. Além desses elementos, há também a presença de elementos metalinguísticos como "quando" e "eles", "pontuação" e "vírgula”. Os elementos considerados indícios de um conceito de coesão textual foram: "repetições”, "quando", "eles", "vírgula”. Segundo esse conceito, é necessário o emprego adequado desses elementos para "maior evolução do texto". No final, chama atenção a referência explícita à coerência textual, que o formando relaciona à estrutura verbal do texto-base, provavelmente, porque, para o formando, os conceitos de coesão e coerência podem ser intercambiáveis.

Já no exemplo (7),

(7) solução $\rightarrow$ No $1^{\circ}$ período, observou-se a repetição do pronome eles. Para desfazê-lo, nomeei os pronomes com os substantivos próprios (Débora e Marcos). Em seguida, usei a elipse antes do verbo perceber. Depois, reiterei as personagens usando pró-forma pronominal eles. $\mathrm{Na} 2^{\mathrm{a}}$ solução, no $2^{\circ}$ período, para ligá-lo \# $1^{\circ}$, utilizei a expressão (verbal), aliás, adverbial temporal ( no momento em que). Já na $3^{\mathrm{a}}$ solução, usei no $3^{\mathrm{o}}$ período a Nominalização \# para ligá-lo ao $2^{\mathrm{o}}$ período. (texto 123 , UNIPUB, grifos nossos).

o enunciador assume, inicialmente, uma atitude apreciativa ao apontar a repetição do pronome "eles" como um problema do texto-base. Em seguida, a postura passa a ser mais explicativa, devido à presença de mais 
elementos metalinguísticos (substantivos próprios, elipse, verbo, pró-forma pronominal eles, adverbial temporal, etc.) e à ausência de modalizadores. Pode-se dizer, ainda, que a presença desses elementos em (7) indica uma noção, mesmo implícita, de coesão textual diferente dos demais exemplos, pois se baseia em uma atitude explicativa, isto é, o sujeito procura usar termos próprios da gramática da língua na tentativa de explicar as alterações efetuadas (YAGUELLO, 1988).

Já em (8),

(8) *Não há necesidade de repetir várias vezes o sujeito "eles". A gramática normativa justifica através do sujeito indeterminado. *As sentenças estão muito longas. Podemos usar pontos finais ou_conjunções. * É preciso simplificar as idéias e concluí-las melhor. Desta forma as mesmas ficarão mais claras. (texto 36, UNIPAR, grifo nosso).

o enunciador também faz uma referência explícita à gramática normativa ao apontar o problema da repetição do "sujeito "eles" no texto-base. Sua atitude apreciativa é marcada pelo emprego de modalizadores nos trechos "não há necessidade de repetir", "muito longas", "É preciso simplificar", "concluí-las melhor", "ficarão mais claras". Podem-se perceber, também em (8), elementos metalinguísticos como "sujeito "eles"”, "sujeito indeterminado", "pontos finais" e "conjunções". A coesão, entendida como o emprego de pronomes, conjunções, sinais de pontuação, foi marcada pelos seguintes elementos "repetir [ [...] o sujeito 'eles", "pontos finais" e "conjunções".

Por sua vez, em

(9) No parágrafo citado podemos perceber vários erros que são condenados pela gramática normativa, dentre eles: não há uma sequência de idéias. Ao mesmo tempo em que falavam do que estava assustando os bezerros, já falavam do caranguejo gigante que os atacava, ocorrendo uma ambigüidade em não sabermos quem os caranguejos haviam atacado, se os bezerros ou a família. Também o uso desnecessário da palavra "que" na primeira linha do $2^{\circ}$ parágrafo. (texto148, UNIPUB, grifo nosso)

o enunciador já revela uma atitude normativa ao apontar os "vários erros" do segundo parágrafo do textobase "que são condenados pela gramática normativa". Dentre os erros apontados, está o fato de não haver uma sequência de ideias. Para o formando, a sequência de ideias transformou-se em tópico gramatical. Os outros erros apontados foram a ambiguidade e o uso desnecessário da palavra "que", palavra esta que constitui um elemento metalinguístico que o aluno não classifica, mas destaca por meio de aspas. Assim, tem-se, além de uma atitude normativa, uma atitude apreciativa. Como indícios de um conceito de coesão foram tomadas a palavra "que" e a ambiguidade apontada nesse parágrafo, já que esta remete ao uso do pronome "eles" pela autora desse texto-base.

De acordo com esse levantamento, pode-se observar que, além dos textos com referências explícitas à coesão e à coerência textuais, já comentados na seção anterior, também há textos em que o conceito de coesão textual está implícito ou só explicitado em função da situação (um exame com uma questão em que se propõe o desenvolvimento de uma atividade específica e de um assunto determinado). Dentre estes últimos, figuram textos em que ocorreram palavras que fazem remissão implícita à coesão textual (17 (85\%) textos de alunos de UNIPAR e 34 (85\%) textos de alunos de UNIPUB) e explícita à coerência textual. Foram $3(15 \%)$ textos de alunos de UNIPAR e $6(15 \%)$ de alunos de UNIPUB. De acordo com o total de textos, percentualmente, pode-se perceber um equilíbrio em ambas as esferas universitárias. Pode-se observar, também, que nesses textos há enunciados com a presença de marcas que indicam atitudes normativa, apreciativa e explicativa, com predominância da apreciativa. É significativo o fato de os estudantes empregarem palavras que fazem referência explícita à coerência textual nos comentários sobre o texto-base e a questão da prova do ENC/2001 tratar de mecanismos coesivos empregados pela autora desse texto.

Parece-nos que as causas desse fato podem ser duas: i) os estudantes confundiram o conceito de coesão textual com o de coerência textual, isto é, misturaram os conceitos; ii) os estudantes concebem a coerência textual como uma consequência de um texto bem formado quanto às ligações coesivas.

Tais referências à coerência textual, misturadas com indícios implícitos de coesão textual, permitem uma comparação com os conceitos de alguns autores consagrados. Segundo esses conceitos, a coerência não se distingue da coesão, engloba-a. Dentre esses autores, vale lembrar Charolles (1997 [1978]), que afirma que Forum linguistic., Florianópolis, v.11, n.4, p.444-456, out./dez.2014. 
a coerência abrange os níveis microestrutural e macroestrutural do texto. O primeiro envolve a superfície textual e o segundo, o nível global, incidindo sobre as relações que se estabelecem entre sequências consecutivas. Nesse conceito, pode-se perceber que a coesão está contida no nível microestrutural.

O resultado da análise desse conjunto de textos sugere que esses alunos apresentam um conceito de coesão textual, que ocorre de forma implícita em um discurso em que se apontam problemas no texto-base. Esse apontamento de problemas indica o predomínio de uma atitude apreciativa. Com isso, pode-se dizer que, nesses textos, também há a reprodução de um discurso didático e que há evidências de um discurso que procura se apropriar de uma terminologia mais técnica, consideradas as condições de produção dessas respostas (o ENC/2001). E, nesse caso, trata-se de um discurso pedagógico, que indica a apropriação de uma metalinguagem gramatical pelo professor para garantir a autoridade de dizer o que diz a partir da instituição escolar (ORLANDI, 1987).

\section{HETEROGENEIDADE MOSTRADA MARCADA: SEM MENÇÃO À COESÃO TEXTUAL; COM MENÇÃO À COERÊNCIA}

Nesta forma de manifestação, temos quatro textos de alunos de UNIPAR e quatro textos de alunos de UNIPUB. Nesses textos, os formandos empregam palavras e/ou expressões que não fazem referência nem específica nem não específica à coesão textual. Entretanto, esses textos apresentam indícios que remetem à coerência textual, por meio das palavras "coerência" e "coerente"; à gramática normativa, por meio das expressões "gramática normativa" e "normas/regras da língua culta"; e à linguística, por meio da palavra "lingüística". Por isso, tais marcas foram tomadas como índices da presença do outro e, assim, também foram relacionadas com a noção de heterogeneidade mostrada marcada.

Vejamos os exemplos (10) e (11):

(10) Certa vez, uma menina escreveu um texto sobre uma família em férias numa ilha. A menina ao escrever cometeu alguns erros. Esses problemas poderiam ser resolvidos se ela tivesse escrito desta forma: Ao adormecer perceberam... Quando derrepente um caranguejo gigante de uma perna só os atacou... Débora a esposa. (texto 63, UNIPAR)

(11) Just: Somente com a mudança da sequência dos acontecimentos e das ações das personagens é possível criar novas opções mais coerentes. (texto 22, UNIPAR)

Em (10), o enunciador aponta os erros no texto-base de forma genérica, apresenta uma solução com a reescrita incompleta de algumas orações em que se destaca a correção de "de repente" do texto-base por "derrepente". Por sua vez, em (11), o aluno refere-se à sequência de acontecimentos do texto-base, sugerindo uma mudança para, assim, torná-lo "coerente”. Por meio da palavra 'coerente' faz uma remissão à coerência textual.

De forma geral, houve, nesses textos, o predomínio de uma reescrita do segundo parágrafo do texto-base e de comentários com a indicação de problemas. Dentre os problemas, estão: a ambiguidade, o vocabulário escasso e as ideias sem sequência. A indicação desses problemas, embora em menor número, não difere dos problemas apontados nas análises feitas com os demais textos nas análises já apresentadas.

Com base na análise, observamos que, nas justificativas desse grupo de textos, não há indícios de conceitos de coesão textual. Essa ausência se destaca pela presença de marcas que remetem à coerência textual, à linguística e à gramática normativa. Essas ocorrências também indicam uma tentativa de apropriação de um discurso mais técnico. A presença de modalizadores no apontamento de problemas e de soluções também é visível, como, por exemplo, "uso desnecessário", "uso adequado", "vocabulário escasso", "a conclusão deveria ser mais concisa". Pode-se dizer, com isso, que, nesse conjunto de textos, também vigora um discurso marcado por atitudes normativa e apreciativa do enunciador, uma vez que predomina o apontamento de problemas no texto-base. Tem-se, então, a presença de um discurso didático-pedagógico. 


\section{CONCLUSÃO}

A partir desta análise, constatamos a presença de marcas linguísticas específicas e não específicas, as quais constituem indícios de conceitos de coesão e de coerência textuais em textos de formandos do curso de Letras. Tais marcas foram relacionadas com a noção de heterogeneidade mostrada marcada, uma vez que inserem o outro no fio do discurso desses acadêmicos. Além dessas marcas, foi constatada também a presença de outras marcas, as quais foram analisadas como representativas de atitudes normativa, apreciativa e explicativa e também relacionadas com a noção de heterogeneidade mostrada marcada. Todas essas marcas indicam um posicionamento enunciativo do enunciador.

Com esses dados, concluímos que, no discurso desses acadêmicos, emergem vozes devidamente marcadas que o caracterizam como heterogêneo. Essas vozes podem ser tomadas como o protesto de quaisquer profissionais do ensino diante do texto de uma menina de 10 anos: "falta coesão", "falta coerência", "texto confuso e sem coerência", "erros de coesão", "problemas de coesão", "frases sem coesão", "falta de coesão e de coerência", "necessidade de coesão e de coerência", "não há coesão e coerência"6 etc. Para esses acadêmicos, essa ocorrência soa como se fosse uma prática comum. No entanto, eles são formandos do curso de Letras, prestes a receberem, na época, o diploma. Então, de onde vem (vêm) essa (s) voz (es)? É nesse ponto que parecem reproduzir um discurso já conhecido, algo "já dito". E é esse "já dito" que faz da heterogeneidade uma característica marcante no discurso desses acadêmicos.

Em se tratando, então, da heterogeneidade, isto é, da relação interdiscursiva que é materializada nesses textos, dois discursos se evidenciam: o discurso didático e o discurso pedagógico. Tais discursos, por conviverem com atitudes normativa e apreciativa, revelam em seu interior um discurso prescritivonormativo. Há que se acrescentar um terceiro discurso, embora não seja o predominante, que se caracteriza por uma atitude explicativa ao descrever o que ocorre no texto-base por meio de uma terminologia gramatical e linguística mais técnica e precisa: o discurso científico. Por meio desses discursos, o formando busca conferir ao texto consistência e credibilidade.

Em relação à concepção de linguagem que embasa o discurso desses alunos, pode-se dizer que predomina uma concepção tradicional de linguagem, uma vez que a postura dos formandos é analisar o texto-base sem considerar as condições de produção desse texto. Como consequência, observa-se na formação acadêmica desses alunos uma concepção de ensino de língua materna de acordo com uma perspectiva prescritivonormativa.

\section{REFERÊNCIAS}

AUTHIER-REVUZ, J. Heterogeneidade(s) enunciativas(s). Tradução de Celane M. Cruz e João Wanderley Geraldi. Cadernos de Estudos Linguísticos, Campinas, n.19, p. 25-42, jul./dez. 1990.

Heterogeneidade mostrada e heterogeneidade constitutiva: elementos para uma abordagem do outro no discurso. In: ___ Entre a transparência e a opacidade: um estudo enunciativo do sentido. Revisão técnica da tradução de Leci Borges Barbisan e Valdir do Nascimento Flores. Porto Alegre: EDIPUCS, 2004. p. 11-80.

BAKHTIN, M. Marxismo e filosofia da linguagem. Tradução de Michel Lahud e Yara. F. Vieira. 8. ed. São Paulo: Hucitec, 1997.

Estética da criação verbal. Tradução Paulo Bezerra. 4. ed. São Paulo: Martins Fontes, 2003.

BEAUGRANDE, R. de; DRESSLER, W. Introduction to Text Linguistics. New York: Longman, 1981.

CASTILHO, A. T de. A língua falada no ensino de português. São Paulo: Contexto, 1998.

\footnotetext{
${ }^{6}$ Baseio-me em texto de Komesu (2006), apresentado no "II Simpósio Internacional sobre práticas escritas na escola” como arguição ao texto "O conceito de coesão em texto de universitários". Segundo Komesu, "[...] os protestos poderiam ser tomados como os de quaisquer profissionais do ensino na relação cotidiana com a produção escrita de alunos" (p. 01).

Forum linguistic., Florianópolis, v.11, n.4, p.444-456, out./dez.2014.
} 
CHAROLLES, M. Introdução aos problemas da coerência dos textos (Abordagem teórica e estudo das práticas pedagógicas). In: GALVES, C.; ORLANDI, E. P.; OTONI, P. (Org.). O texto: leitura \& escrita. Tradução Charlote Galves, Eni Puccinelli Orlandi e Paulo Otoni. 2. ed. Campinas: Pontes, 1997. p. 39-90.

CORRÊA, M. L. G. A produção escrita de formandos em Letras: a experiência do provão. In: OLIVEIRA, M. de (Org.). Lingua Portuguesa em São Paulo: 450 anos. São Paulo: Associação Editoria Humanitas, 2006. p.141-165.

KOCH, I. V. O texto e a construção dos sentidos. São Paulo: Contexto, 1997.

KOMESU, F. Arguição ao texto $\mathrm{O}$ conceito de coesão em textos de universitários. In: Simpósio Internacional sobre Práticas Escritas na Escola: letramento e representação, 2., 2006, São Paulo. [Simpósio]... São Paulo: USP, 2006. (CD-ROM)

MAINGUENEAU, D. L' Archive. In: L'Analyse du discours: introduction aux lectures de l'archive.

Paris: Hachette, 1991. p. 09-28.

MARCUSCHI, L. A. Anáfora Indireta: o barco textual e suas âncoras. Revista de Letras da UFPR, Curitiba, v. 56, jul./dez., p. 217-258, 2001. Versão revista do texto apresentado na IV Jornada do CELSUL-UFPR, nov. 2000.

A repetição na língua falada como estratégia de formulação textual. In: KOCH, I. G. V. (Org.) Gramática do Português Falado VI: Desenvolvimentos. 2. ed. Campinas: Editora Unicamp, 2002. p. 105-141.

ORLANDI, E. P. A linguagem e seu funcionamento: as formas do discurso. 2. ed. São Paulo: Pontes, 1987.

PAULA, O. de. Noções de coesão na visão de formandos em Letras. 2008. $174 \mathrm{f}$. Tese (Doutorado em Letras) Faculdade de Filosofia, Letras e Ciências Humanas, Universidade de São Paulo, São Paulo, 2008.

POSSENTI, S. Discurso, Estilo e Subjetividade. São Paulo: Martins Fontes, 1993.

PROVÃO 2001- Exame Nacional de Cursos. Disponível em: $<$ http://www 1.folha.uol.com.br/folha/educacao/2001-provao-letras.pdf>. Acesso em: 01 maio 2008.

YAGUELLO, M. Le sentiment de la langue. In: Catalogue des idées recues sur la langue. Paris:

Editions du Seuil, 1988. p. 11-14.

Recebido em 29/o3/2014. Aprovado em 23/04/15. 